\title{
Evaluating the Risk Management on Disabled Athlete Activities in Malaysia
}

\author{
Jaffry Zakaria, Zulakbal Abd Karim, Azali Rahmat, Sanmuga Nathan K. Jeganathan \\ Faculty of Sport Science and Coaching, Sultan Idris Education University, Perak, Malaysia \\ Email: jaffry@fsskj.upsi.edu.my
}

How to cite this paper: Zakaria, J., Karim, Z.A., Rahmat, A. and Jeganathan, S.N.K. (2017) Evaluating the Risk Management on Disabled Athlete Activities in Malaysia. Open Access Library Journal, 4: e4011. https://doi.org/10.4236/oalib.1104011

Received: October 9, 2017

Accepted: November 21, 2017

Published: November 24, 2017

Copyright $\odot 2017$ by authors and Open Access Library Inc.

This work is licensed under the Creative Commons Attribution International License (CC BY 4.0).

http://creativecommons.org/licenses/by/4.0/

\section{cc) (i) Open Access}

\begin{abstract}
This article aims to look upon the guidelines regarding the preparation of facilities and risk management of training activities for disable athlete. The facilities and appropriate training activities are one of the vital entities to prepare them towards better performance. Suitable facilities for every group will give advantages toward any service provider; thus their facilities will always be users' choice. However, special facilities for this group are also needed to be taken into consideration to ensure equality for them. This group needs to be given attention and helps to ensure that their success in sports area can be highlighted and they may experience what was felt by other normal athletes, indirectly. But, the facilities and non-user-friendly risk management of the training practices result to the limitation of their mobility and potential in our country's sports arena. Lack of scientific material regarding disabled athletes in risk management field also contributes to the reason why authors wish to share discussion to give precise and useful information for readers.
\end{abstract}

\section{Subject Areas}

Education, Sports Science

\section{Keywords}

Risk Management, Facilities, Disabled Athlete, Management

\section{Introduction}

User-friendly sport facilities are one of the benefits that need to be available in services offered to every level of society. Awareness about the importance of giving the best and perfect facilities for disable athlete is greatly desired to 
overcome the risk of accident and injuries. Facilities for them must be given emphasis by any organization that offers sport facilities so those they may enjoy convenient sport surrounding. However, this group of people's wishes to continuously be given a chance to achieve higher sport performance that will be obstructed if special facilities for them are not available at sport facilities. Accordingly, the authorities should take action to provide the best and user-friendly sport facilities for the disabled. In Malaysia, private and business sectors would follow because of the need to achieve a developed nation as well as to improve the quality of life of its citizens [1].

For the sport facilities that have long been built, renovation needs to be done to prepare the facilities for disable people to ease and help them undergoing training like the normal athletes would do. The government also needs to take proactive steps to enhance the involvement of disable people in sports. At once, their welfare will be defended and they will be able to undertake the equivalent sport activities with the other normal people.

\section{Background of the Study}

Disable people in Malaysia has gotten serious attention from the government, especially from Department of Social Welfare Malaysia. While, in sports field every disable athletes will be placed under Malaysian Paralympic Council. The definition gave by Ministry of Woman, Family and Community Development is someone those with long-term physical, mental, intellectual or sensory shortcomings that when interacting with various barriers can restrict their full and effective participation in society [2].

Ministry of youth and Sport Malaysia has provided athletic facilities that are complete and comfortable for disabled athlete. The development of disabled athlete's sports facilities, which cost RM 50 million, shows the government's seriousness in improving the performance and excellence for disabled athletes. This sports complex features international dormitories, swimming pools, sports courts and all the disabled facilities.

This definition refers to the variety of disability experienced by individual whether physically or mentally. According to the Malaysian standards MS 1184:2002: Clause 2(4) and Clause 2(2), disabled person was defined as someone who lost the ability from the aspect of physical, hearing or eyesight and the combination of any criteria stated that affect their mobility or facilities usage at premises. Meanwhile, according to U.S Department of Health and Human Services, they define disable person as someone who has obstructed movement function (different with people who has body ability) and as a solution towards those obstruction, special building design, equipment choice and the arrangement outside the area made available for them.

As a whole, it can be summarized that disable people is the group of people who has disabilities in term of their physical and mental sense as compared to those perfect individual. This disability exists whether on the body, lack of sense abilities, which are eyesight, hearing and/or speech and thinking. 


\section{Literature Review}

The preparation of perfect and appropriate facilities for disable group of people will help them indirectly to undergo daily life effectively. Several codes of practices were introduced by Scientific and Industrial Research Institute of Malaysia (SIRIM) to ensure the procedure and practice used to help the disabled people which are;

\section{Standard Code of Practice on Access for Disabled Persons to Public Buildings. (First Revision) (MS 1184:2002)}

This standard code of practise was issued by SIRIM in 1991 and improvement has been made to be used again in 2002 after the government's principal and commitment towards this group was improvised. This code gives the stress and guidelines regarding the specification and standard for the disable group that need to be made available inside a building. The available facilities must meet the requirement of disable people to help ease their daily movement when doing their business inside the building [3]. Standard Code of Practice is very important in risk management and it was the first process in risk management methodology [4]. This code is compulsory to be used at all building and premises that are used by disable people whether as worker, visitor or visiting public. However, for building of housing type, this code will be automatically cancelled. Among the buildings involved with this standard code of practise are;

i) Office, bank, post office, shopping mall, hotel and administration office and another commercial offices;

ii) Transportation building, which is bus station, train station, airport, ferry terminal, car park building and factory;

iii) Hospital, medical center, clinic and another health center, and welfare institution;

iv) Restaurant, concert hall, cinema, theater hall, convention building, community building, swimming pool, sports complex, entertainment center and recreation center;

v) School, hostel, collage, university, zoo, museum, art gallery, library, exhibition hall and another public building that involve disable people as visitors, tenant or worker and;

vi) Religious building

This SIRIM standard code of practice has given emphasis to the need of disable people to go through and arrive to a facility or building in which can help ease their movement. Access to disable-friendly facilities is greatly vital in this code where their movement is limited and if the access to all of the facilities is extremely easy, they will be able to move like another normal individual. The emphasis given in SIRIM standard code of practice regarding route means direct route without any disturbance to ensure the disabled people enter and move inside the building by using wheelchair. The need of route for disabled people is totally important because of the limitation of their mobility. Therefore, this SIRIM's standard code of practice defined as route or accessibility of disabled 
people, specifically. According to this standard code of practice, disabled route can be defined as the continuous route to enter or move inside the building without disturbance when they use the wheelchair. This SIRIM code cover these matters which are:

\section{Circulation Space}

Circulation space means the route or hallway corridor, lobby, hall-way or lift path for the route between the sections inside the building.

\section{Floor Entrance}

Floor entrance means floor level where people who use the building will usually enter, but does not include the basement or utility space.

\section{Guiding Blocks}

Guiding blocks means specific tiles that are installed that covers the surface of route and it was arranged according to specific arrangement which can guide the people with eyesight disability.

\section{Name and Direction Markers}

Name and direction markers mean the symbols or direction markers that can help the disabled people to know the location or the direction of provided facilities for them. The sign or symbol used must have appropriate size, effective design and must be put at the place that can give the benefit for the disabled whether in audio or visual type.

\section{Risk Management Responsibilities}

As the provider of facilities and training services to disable athlete, the coach or the management authorities need to give attention towards following several matters to ensure the control of training activities is safe. This is because the movement of disabled athlete is very limited and they often need help from the assistants whether before, during and after training. The matters that need to be taken into consideration are:

\section{Surrounding Area}

The surrounding area of the activity must undergo inspection before and after training so there will be any obstacles and hazardous object. If the activity conducted at indoor surrounding, that area needs to be free from any obstacles and surrounding disturbance. Specific activity areas need to be ensured that it is clean, save and dry. Meanwhile all of the arena lines need to be obvious and coloured again if there is any deficiency to avoid confusion when the activities take place. Safe ventilation need to be ensured to retain the quality and the temperature of the surrounding. Besides that, the commonly-used by athletes surrounding such as locker, toilet and bathroom has to undergo periodic monitoring from the safety aspect. For instance, the area of floor surface must be ensured that there is no slippery floor area and can lead to injuries.

\section{Equipment}

Athlete need to be supplied with the suitable equipment with the conducted sports so there will be no misuse of equipment which can lead to injuries. Therefore, several following matters need to be followed to control the things regarding equipment. Firstly, control the number of equipment. The equipment 
used must be enough and excessive equipment does not happen which can lead to the misuse of those equipment. Secondly, equipment used should be maintained prior to training or competition.

Those equipments also should be routinely inspected not only on the run before or during the activity.

Next, equipment should be used according to usage guidelines or according to their specific use and not misused. Equipment should also be compatible with the size of the athlete using it. For example, the junior athlete and senior athlete is very different from the aspect of equipment size. Lastly, the management has to ensure and review the warranty of the equipment purchased before the equipment is used. Also [5] the instructor or coach can also help developing strategies to reduce barriers and enhance facilitators in order to increase the number of people with physical disabilities to participate in sport, also at an elite level.

\section{Activity Supervision Planning}

Coaches should do supervision for all activities whether during training or in competition. If they have assistants or volunteers, they need to be trained and equipped with sufficient knowledge regarding disabled athletes. During regular competitions or training, qualified medical personnel should be provided in the event of an accident or undesired injury. The coaches also need to select activities that are age appropriate and be prepared to modify activities to accommodate all abilities [6].

\section{Injury Prevention}

Prevention of injuries is a key factor that should be emphasized before, during and after training. While prevention of injury is an important issue for all athletes, the impact of a sporting injury to an individual with a disability may severely affect their ability to function independently on a daily basis [7]. There are various factors that can be a contributor to injury prevention as well as injuries risk reduction. Continuous assessment among athletes on their skills is strongly encouraged so that training and activities are conducted according to the rate and intensity of training according to their ability. Whereas if training is more geared towards specific sports or individuals, the coach should provide a specific training plan in the exercise of the sport. This is because if a plan or periodic exercise that is not systematic and planned later can contribute to athlete injury during training or competition.

\section{Conclusion}

Based on the discussion in this article, a good risk management assessment can minimize the risk among disabled athletes. Risk management practices that are unfriendly athlete's disability will further increase their burden. The objective of risk management is to control the impact of unforeseen issues or accidents that take place within a project and risk management is thus a proactive process [3]. However, if all the best risk planning and risk management practices can be 
taken by the responsible parties, then the opportunities for this sport can be equally shared with other normal athletes. Indirectly, the country can produce high-quality and high-quality Paralympic athletes as well as bring the country's name to life.

\section{References}

[1] Hazreena, H. and Naziaty, M.Y. (2012) Development of Accessible Design in Malaysia. Procedia Social and Behavioral Sciences, 68, 121-133.

https://doi.org/10.1016/j.sbspro.2012.12.212

[2] Department of Society \& Welfare (2011) Transformational Plan Department of Society and Welfare 2011-2015. JKM, Kuala Lumpur.

[3] Handstad, D.V. (2012) Risk Management in Major Sporting Events: A Participating National Olympic Team's Perspective. Event Management, 16, 189-201. https://doi.org/10.3727/152599512X13459279626683

[4] Safe Work Australia (2011) How to Manage Work Health and Safety Risks: Code of Practice. Safe Work Australia, Sydney.

[5] Jaarsma, E. (2014) Sports Participation and Physical Disabilities. Scandinavian Journal of Medicine and Science in Sports, 24, 54-73.

[6] Heidi, I.S. and Georgia, C.F. (2008) Promotion of Physical Activity in Individuals with Intelectual Disability. Journal of Salud Publica de Mexico, 50, 178-184. https://doi.org/10.1590/S0036-36342008000800011

[7] Osman, H.A., Ayser, W.H., Ian, B., Jiri, D. and Richard, W. (2015) Enhancing Performance and Sport Injury Prevention in Disability Sport: Moving Forwards in the Field of Football. British Journal of Sport Medicine, 49, 566-568.

https://doi.org/10.1136/bjsports-2013-093058

Open Access Library

Submit or recommend next manuscript to OALib Journal and we will provide best service for you:

- Publication frequency: Monthly

- 9 subject areas of science, technology and medicine

- Fair and rigorous peer-review system

- Fast publication process

- Article promotion in various social networking sites (LinkedIn, Facebook, Twitter, etc.)

- Maximum dissemination of your research work

Submit Your Paper Online: Click Here to Submit

Or Contact service@oalib.com 